\title{
Brain natriuretic peptide is released from human astrocytoma cell line U373MG under hypoxia: a possible role in anti-apoptosis
}

\author{
Chisato Katoh, Tomohiro Osanai, Hirofumi Tomita and Ken Okumura \\ Department of Cardiology, Hirosaki University Graduate School of Medicine, 5 Zaifu-cho, Hirosaki 036-8562, Japan \\ (Correspondence should be addressed to T Osanai; Email: osanait@cc.hirosaki-u.ac.jp)
}

\begin{abstract}
We have recently shown that the plasma brain-type natriuretic peptide (BNP) level is elevated in acute ischemic stroke patients, but the origin and role of BNP remain unclear. We investigated whether human astrocytes secrete BNP under hypoxia, and if so, what signaling pathway is involved, and what is the role of BNP. Human astrocytoma cell line U373MG was exposed to hypoxia by Anaeropack. BNP gene expression was increased by $3 \cdot 9 \pm 2 \cdot 5$ - and $6 \cdot 5 \pm 2 \cdot 9$-fold at 12 and $24 \mathrm{~h}$ after hypoxia respectively $(n=6$, both $P<0 \cdot 05)$ and was associated with twofold increase in BNP protein at $24 \mathrm{~h}$. BNP release in the culture media ( $\mathrm{pg} / \mathrm{mg}$ protein) was elevated from $1 \cdot 8 \pm 1 \cdot 8$ under normoxia to $13 \cdot 5 \pm 7 \cdot 8$ after 24 -h hypoxia $(n=9, P<0 \cdot 01$ versus normoxia). Western blot revealed the tyrosine ${ }^{415}$ phosphorylation of tyrosine kinase
\end{abstract}

c-Src under hypoxia. Treatment of the cells with tyrosine kinase inhibitor PP1 abolished hypoxia-induced increase in BNP expression and release. In the cells exposed to hypoxia, caspase activity and apoptosis, measured by annexin$\mathrm{V}$-propidium iodide kit, were increased at $24 \mathrm{~h}$ compared with the cells under normoxia $(n=5$, both $P<0 \cdot 05)$. It was further increased in the cells transfected with siRNA for natriuretic peptide precursor $\mathrm{B}(n=6$, both $P<0 \cdot 05)$ and reversed by administration of exogenous BNP $(P<0 \cdot 01)$. In conclusion, hypoxia increased BNP expression and release in human astrocytoma cell line U373MG through c-Src activation. BNP may play a pivotal role in anti-apoptosis of astrocytes under hypoxia.

Journal of Endocrinology (2011) 208, 51-57

\section{Introduction}

Brain-type natriuretic peptide (BNP, also known as Nppb) is secreted from cardiac ventricles predominantly (Mukoyama et al. 1991, Yasue et al. 1994, Bonow 1996), and the plasma level of BNP is elevated in various cardiac disorders (Bonow 1996, Omland et al. 1996). To date, BNP is recognized as a useful biochemical marker for the severity of congestive heart failure. Recently, it has been shown that the plasma level of BNP is elevated in ischemic stroke patients at the acute phase and is correlated with blood pressure (Nakagawa et al. 2005). The plasma level of $\mathrm{N}$-terminal pro-brain natriuretic peptide is also elevated in acute ischemic stroke patients (Iltumur $e t$ al. 2006), and left atrium or appendage abnormality is associated with BNP levels. More recently, we have shown that the plasma level of BNP is transiently increased in acute ischemic stroke patients with large artery atherosclerosis and reflects infarct volume and the severity of acute ischemic stroke (Tomita et al. 2008). However, this was independent of heart disease and the origin and role of BNP still remain unclear.

Astrocytes are the principal housekeeping cells of the nervous system, and their roles are to shuttle metabolites and waste products and to participate in the formation of the blood-brain barrier (Chen \& Swanson 2003). Also, astrocytes have recently been implicated in the local control of blood flow and synaptic transmission by gliotransmitters (Zonta et al. 2003, Takano et al. 2006, Iadecola \& Nedergaard 2007). Compared with ischemic infarcts that are total death of neurons, astrocytes, and the vasculature, transient ischemic attack is frequently associated with selective neuronal injury with little, if any, loss of astrocytes (Nedergaard 1988). Therefore, functional recovery is expected in transient ischemic attack, and it is conceivable that stroke injury is primarily a consequence of the failure of astrocytes to support the essential metabolic needs of neurons. Astrocytes release many transmitters and neurotrophic factors which are concerned with the paracrine or autocrine signaling between astrocytes and neurons, endothelial cells and microglial cells, or astrocytes per se (Takano et al. 2009). Furthermore, the expression of BNP mRNA in rat brain tissues is increased after 24-h occlusion of the middle cerebral artery (Brosnan et al. 1999). Overall, it is most likely that BNP is upregulated in the ischemic brain and secreted from the brain-constituting cells such as astrocytes. In this study, we investigated whether BNP expression is enhanced in cultured human astrocytoma cell line U373MG when exposed to hypoxia, and if so, what signaling pathway is involved. We also examined whether endogenous BNP suppresses apoptosis. 


\section{Materials and Methods}

\section{Materials}

The Src family tyrosine kinase inhibitor PP1 $\left(\mathrm{IC}_{50}: 170 \mathrm{nM}\right.$ for p $60^{\mathrm{src}}$ ) was purchased from Biomol, Plymouth Meeting, PA, USA. Aneropack and hypoxic chamber were obtained from Mitsubishi Gas Chemistry, Tokyo, Japan. QIA shredder and RNeasy Protect Mini Kit were from Qiagen. TaqMan Reverse Transcription Reagent and TaqMan Universal PCR Master Mix were from Applied Biosystems, Foster City, CA, USA. RIPA lysis buffer, anti-BNP antibody for the C-terminus of human BNP, anti-Src, anti-phosphorylated c-Src (p-c-Src), and anti-glyceraldehyde-3-phosphate-dehydrogenase (GAPDH) antibodies were from Santa Cruz Biotechnology, Inc. (Santa Cruz, CA, USA). ECL plus detection system was from Amersham Pharmacia Biotech. Natriuretic peptide precursor B (NPPB)-annealed siGENOME SMART pool (Cat; M-019676-00), siCONTROL Non-Targeting siRNA\#1 (Cat; D-001210-01), and DharmaFECT 2 (Cat; T-200202) were all from Dharmacon, Inc. (Lafayette, CO, USA). CaspSCREEN Flow Cytometric Apoptosis Detection Kit was from BioVision (Mountain View, CA, USA). Human BNP was purchased from Sigma Chemical Co.

\section{Cell culture}

U373MG cells, an established cell line derived from human astrocytoma, were grown in DMEM (Gibco) supplemented with $10 \%$ fetal bovine serum under $5 \% \mathrm{CO}_{2}$ at $37^{\circ} \mathrm{C}$. Primary cultured astrocytes (\#CC-2565, Clontics, Sanko Junyaku Co. Ltd, Tokyo, Japan) were grown in the recommended medium (\#CC-3186, Clontics). When inhibitors were used, the cells were pretreated with serum-free DMEM containing inhibitors for $30 \mathrm{~min}$ before exposure to hypoxia.

\section{Hypoxic stimulation}

The cells were placed in the hypoxic chamber with the Anaeropack, a disposable oxygen-absorbing and $\mathrm{CO}_{2}-$ generating agent, and were incubated at $37^{\circ} \mathrm{C}$ for the indicated time. The control cells were incubated at $37^{\circ} \mathrm{C}$ in an atmosphere of $21 \% \mathrm{O}_{2}$ and $5 \% \mathrm{CO}_{2}$ for the same duration as the hypoxic cells. The Anaeropack started to absorb oxygen within $1 \mathrm{~min}$; oxygen tension inside the box dropped to $1 \mathrm{mmHg}$ within $1 \mathrm{~h}\left(\mathrm{O}_{2}<1 \%, \mathrm{CO}_{2}\right.$ around $\left.5 \%\right)$, and it was continued for 24 h (Kamiya et al. 1998).

\section{Real-time quantitative RT-PCR}

Total RNA was extracted from the cells using QIA shredder and RNeasy Protect Mini Kit. RNA quality and quantity were assessed by the NanoDrop ND-1000 spectrophotometer (NanoDrop Technologies, Wilmington, DE, USA). The RNA was transcribed into the cDNA by two-step RT reaction protocol with the TaqMan Reverse Transcription Reagent according to the manufacturer's instructions. Quantitative RT-PCR was performed with TaqMan Universal PCR Master Mix in duplicate using an ABI PRISM 7700 Sequence Detector (Applied Biosystems). The specific primers and the probe were purchased from Applied Biosystems for detecting NPPB (Assay ID: Hs00173590_m1) and human GAPDH (Assay ID: Hs99999905_m1). For quantitative analysis, BNP mRNA was normalized to GAPDH as the housekeeping gene.

\section{Western blot analysis}

The cells were harvested, pelleted, and resuspended in RIPA lysis buffer. Equal amounts of protein were applied to SDS-PAGE (5-20\% gradient gel). After blocking for $1 \mathrm{~h}$, the membranes were incubated with anti-BNP (1:1000 dilution), anti-Src (1:500 dilution), anti-p-c-Src (1:200 dilution), and anti-GAPDH (1:500 dilution) antibodies at appropriate time and followed by $1 \mathrm{~h}$ incubation with the secondary antibody. The immunoreactive bands were detected by ECL plus detection system. Changes in localization and expression were analyzed using the specific computer software Scion Image (Scion Corporation, Frederick, Maryland, USA).

\section{Measurement of $B N P$}

BNP was measured by chemiluminescent enzyme immunoassay (CLEIA) after partial purification. Briefly, after the cells were placed in the hypoxic chamber for $24 \mathrm{~h}$, the culture media were collected and loaded to Sep-Pak C18 cartridges. After washing with water, the absorbed materials were eluted with 50\% acetonitrile and submitted to CLEIA. Cellular protein was determined by Bradford method.

\section{$R N A$ interference}

U373MG cells were transfected with NPPB-annealed siGENOME SMART pool. As a negative control, we used a siCONTROL Non-Targeting siRNA\#1. Cells were transfected by siRNA (final concentration $100 \mathrm{nM}$ ) at $70-80 \%$ confluency by the use of transfection reagent, DharmaFECT 2, in the complete medium according to the manufacturer's instructions. The medium was changed at $40 \mathrm{~h}$ after transfection, and the cells were stimulated by hypoxia in the free medium for $24 \mathrm{~h}$.

\section{Caspases assay for apoptosis detection}

The activation of caspases was measured by flow cytometry assay by CaspSCREEN Flow Cytometric Apoptosis Detection Kit according to the manufacturer's instruction. Briefly, the cells were trypsinized, washed with cold PBS twice, and incubated with CaspSCREEN Flow Cytometric Apoptosis Detection Kit at $37^{\circ} \mathrm{C}$ for $20 \mathrm{~min}$ in the dark. The fluorescence intensity of the cleaved substrate [(aspartyl $)_{2^{-}}$Rhodamine 110] was measured using FACScan (Becton Dickinson, San Jose, CA, USA) by excitation at $488 \mathrm{~nm}$ and emission at $530 \mathrm{~nm}$. 
Annexin-V and propidium iodide assay for apoptosis

Flow cytometric analysis with an apoptosis detection kit was used for assessment of apoptotic cell death. Briefly, the cells were trypsinized, washed with cold PBS twice, and incubated in the binding buffer $(10 \mathrm{mM}$ HEPES, $140 \mathrm{mM} \mathrm{NaCl}$, and $2.5 \mathrm{mM} \mathrm{CaCl}_{2}$ ) with annexin-V-FITC and propidium iodide (PI) for $10 \mathrm{~min}$ on ice in the dark. The sample was analyzed using a dual-laser FACS Vantage SE flow cytometer (Becton Dickinson, Mountain View, CA, USA) within a $1 \mathrm{~h}$ period. The percentages of apoptotic cells for each sample were estimated.

\section{Statistical analysis}

Results are expressed as mean \pm one S.D. Data were analyzed using one-way ANOVA and two-way ANOVA when they were appropriate. The Bonferroni test was used for comparison of multiple datasets as post hoc testing. All tests were considered to be statistically significant at $P<0 \cdot 05$.

\section{Results}

Effect of hypoxia on BNP expression and release in human astrocytoma U373MG cells and primary cultured astrocytes

As shown in Fig. 1A, exposure of the U373MG cells to hypoxia increased the gene expression of $B N P$ in a timedependent manner. The ratio of BNP to GAPDH mRNA was increased by $3.9 \pm 2 \cdot 5$-fold after $12 \mathrm{~h}$ hypoxia and further increased by $6 \cdot 5 \pm 2 \cdot 9$-fold after 24 h hypoxia compared with that in normoxia $(n=6$, both $P<0 \cdot 05)$. Figure $1 \mathrm{~B}$ illustrates the representative bands expression for BNP protein under $24 \mathrm{~h}$ hypoxia. The immunoreactive band for BNP protein was increased under hypoxia. The ratio of BNP to GAPDH protein was increased by $2 \cdot 0 \pm 0 \cdot 8$-fold after $24 \mathrm{~h}$ hypoxia $(n=4, P=0 \cdot 028)$. As shown in Fig. $1 \mathrm{C}, \mathrm{BNP}$ in the culture media (pg/mg protein) was elevated from $1 \cdot 8 \pm 1 \cdot 8$ under normoxia to $13 \cdot 5 \pm 7 \cdot 8$ after 24 h hypoxia $(n=9, P<0 \cdot 01$ versus normoxia). In primary cultured astrocytes (passage 3 ), it was elevated from $24 \cdot 7 \pm 1.5 \mathrm{pg} / \mathrm{mg}$ protein under normoxia to $45 \cdot 2 \pm 4.5 \mathrm{pg} / \mathrm{mg}$ protein after $24 \mathrm{~h}$ hypoxia $(n=6, P<0 \cdot 05$ versus normoxia).

Role of $c-$ Src in regulation of $B N P$ gene and protein expression under hypoxia

Figure 2A illustrates the representative bands for hypoxiainduced tyrosine phosphorylation of c-Src. The phosphorylation of c-Src was increased by $2 \cdot 0 \pm 0 \cdot 4$-fold at $30 \mathrm{~min}$ after exposure to hypoxia $(n=4, P=0 \cdot 005)$. Pretreatment of the cells with PP1 at $50 \mu \mathrm{M}$ for $30 \mathrm{~min}$ suppressed tyrosine phosphorylation of c-Src. As shown in Fig. 2B, pretreatment of the cells with PP1 at $50 \mu \mathrm{M}$ abolished hypoxia-induced increase in the ratio of $B N P$ to GAPDH mRNA at $24 \mathrm{~h}$

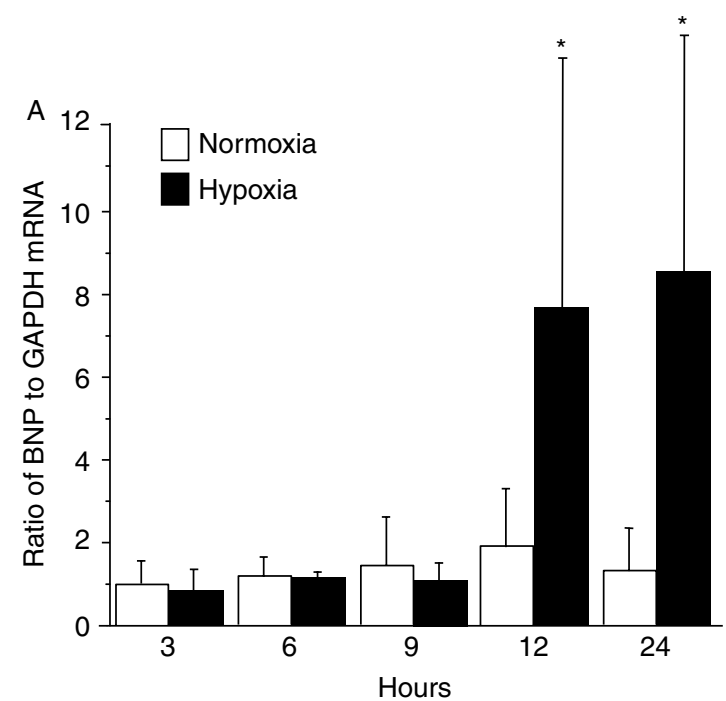

B
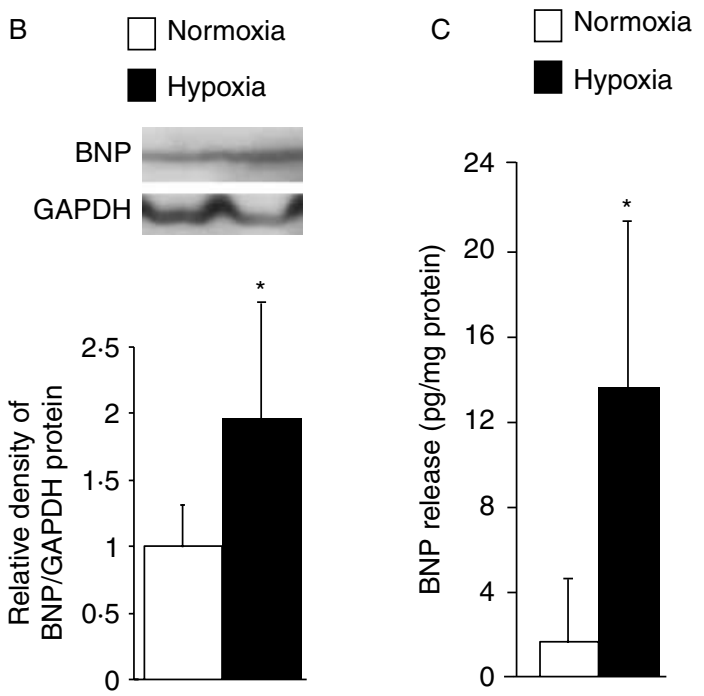

Figure 1 Upregulation of brain-type natriuretic peptide (BNP) expression and release by hypoxia in human astrocytoma cell line U373MG. (A) Bar graphs show the ratio of BNP gene expression normalized by the glyceraldehyde-3-phosphate-dehydrogenase (GAPDH). ${ }^{*} P<0.05$ versus normoxia corresponding to each time $(n=6)$. (B) Representative bands for BNP and GAPDH in western blot analysis. Bar graphs show the results of densitometric analysis of BNP protein compared with normoxia (left: open bar). ${ }^{*} P=0 \cdot 028$ versus normoxia without PP1 $(n=4)$. (C) Bar graphs show the release of BNP. ${ }^{*} P<0 \cdot 01$ versus normoxia $(n=9)$.

without affecting the baseline level under normoxia. PP1 at $50 \mu \mathrm{M}$ also blocked hypoxia-induced increase in BNP protein (Fig. 2C) and release (Fig. 2D).

\section{Effect of BNP on caspase activity in human astrocytoma U373MG cells}

The activity of caspases was analyzed after 24-h hypoxia. As shown in Fig. $3 \mathrm{~A}$ and $\mathrm{B}$, the activity of caspases was increased by $2 \cdot 5 \pm 0 \cdot 2$-fold after $24-\mathrm{h}$ hypoxia compared with that in 
A
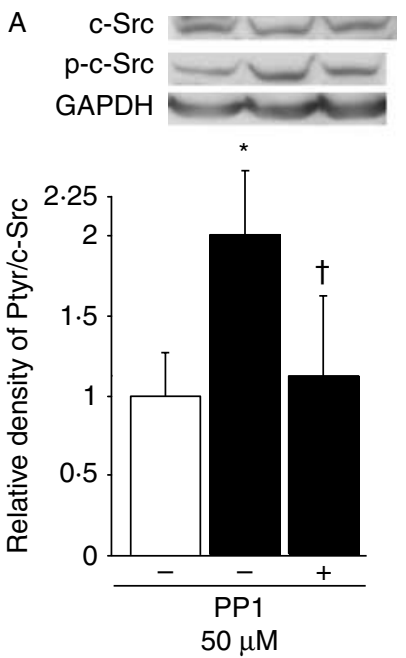

C
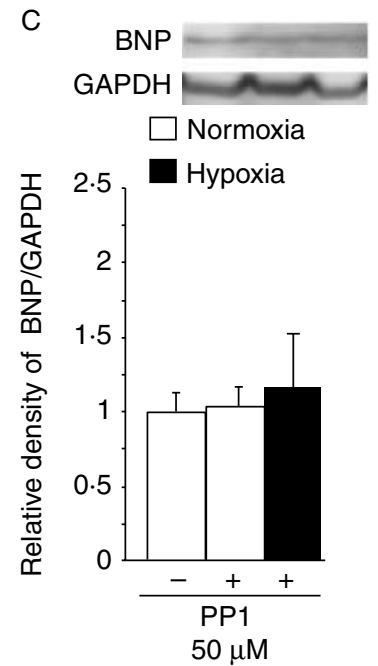

B

\section{$\square$ Normoxia \\ Hypoxia}

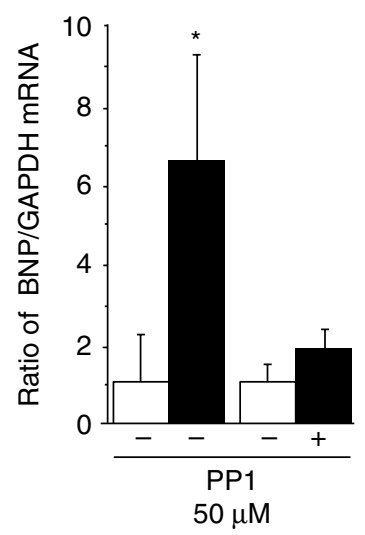

D
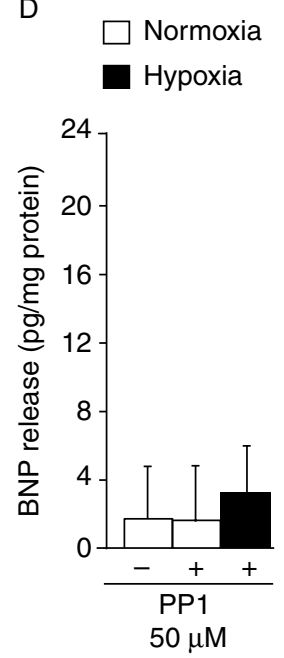

Figure 2 Role of tyrosine kinase of $\mathrm{c}-\mathrm{Src}$ in the regulation of braintype natriuretic peptide $(B N P)$ gene expression. $(A)$ Representative bands for c-Src, p-c-Src, and glyceraldehyde-3-phosphate dehydrogenase (GAPDH) in western blot analysis. Bar graphs show the results of densitometric analysis of tyrosine phosphorylation of c-Src compared with normoxia (left: open bar). ${ }^{*} P=0 \cdot 005$ versus normoxia and ${ }^{\dagger} P=0 \cdot 013$ versus hypoxia $(n=4)$. (B) Effects of $\mathrm{C}$-Src inhibitor PP1 on BNP gene expression. Bar graphs show the $B N P$ gene expression normalized by GAPDH. ${ }^{*} P<0 \cdot 001$ versus normoxia without PP1 $(n=6)$. (C) Effects of c-Src inhibitor PP1 on BNP protein expression. Representative bands for BNP and GAPDH in western blot analysis. Bar graphs show the results of densitometric analysis of BNP protein compared with normoxia (left: open bar) $(n=4)$. (D) Effects of c-Src inhibitor PP1 on BNP release. Bar graphs show the release of $\mathrm{BNP}(n=9)$.

normoxia ( $n=5, P<0 \cdot 001)$, suggesting that hypoxia induced apoptosis in human astrocytoma U373MG cells. To investigate the role of released BNP, we performed the lossof-function test by transfecting a specific siRNA for NPPB to the cells. BNP gene and protein expressions were suppressed by $83 \pm 8$ and $80 \pm 10 \%$ respectively in the U373MG cells $(P<0 \cdot 01)$ at $40 \mathrm{~h}$ after transfection with the siRNA of NPPB

compared with the non-treated control cells. They were unchanged in the cells transfected with an siCONTROL Non-Targeting siRNA\#1. The activity of caspases in the BNP knockdown cells was increased by $3 \cdot 2 \pm 0 \cdot 4$-fold after 24-h hypoxia compared with that in normoxia $(n=5$, $P<0 \cdot 001$ ) (Fig. 3B) and was significantly greater than that in the cells transfected with non-targeting control siRNA. As shown in Fig. 3C, the administration of exogenous BNP at $10^{-7}$ and $10^{-6} \mathrm{M}$ reversed the activity of caspase in the BNP knockdown cells respectively $(n=6$, both $P<0 \cdot 01)$. These suggest that transfection by siRNA of NPPB increased the number of apoptotic cells, and the administration of exogenous BNP rescued it.

\section{Effect of BNP on hypoxia-induced apoptosis in human} astrocytoma U373MG cells

The percentage of apoptotic cells was increased from 1.2 $\pm 0 \cdot 2 \%$ in normoxia to $4 \cdot 2 \pm 1 \cdot 5 \%$ in hypoxia for $24 \mathrm{~h}(n=5$, $P<0 \cdot 05)$ (Fig. 4A and B). The percentage of apoptotic cells in the BNP knockdown cells was increased to $6 \cdot 2 \pm 1 \cdot 1 \%$ after 24-h hypoxia, and it was greater than that in the cells in normoxia and in the cells transfected with non-targeting control siRNA in hypoxia $(n=6$, both $P<0 \cdot 05)$. The administration of exogenous $\mathrm{BNP}$ at $10^{-7}$ and $10^{-6} \mathrm{M}$ reversed its percentages to $4 \cdot 5 \pm 1 \cdot 3$ and $4 \cdot 2 \pm 1 \cdot 2 \%$ respectively in the BNP knockdown cells $(n=6$, both $P<0 \cdot 01)$.

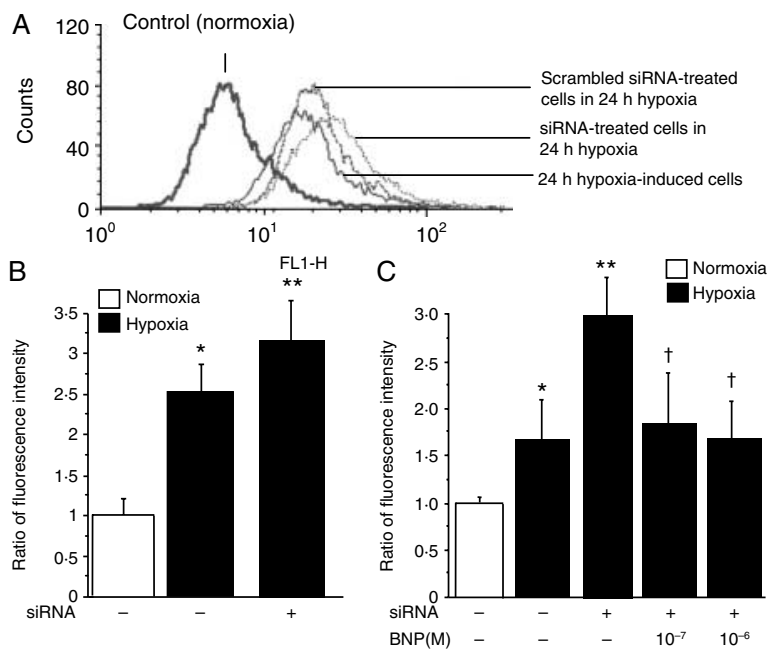

Figure 3 Flow cytometric analysis of caspase activity in human astrocytoma cell line U373MG. (A) Fluorescent intensity was monitored by flow cytometry. Representative charts of flow cytometry in the cells with or without transfection of siRNA or scrambled siRNA under normoxia or hypoxia. (B) Bar graphs show the caspase activity under normoxia and hypoxia with and without BNP knockdown. ${ }^{*} P<0 \cdot 001$ versus normoxia. ${ }^{* *} P<0 \cdot 001$ versus hypoxia $(n=5)$. (C) Bar graphs show the caspase activity due to exogenous BNP. ${ }^{*} P<0.01$ versus normoxia. ${ }^{* *} P<0.01$ versus hypoxia. ${ }^{\dagger} P<0.01$ versus hypoxia in siRNA without exogenous $\mathrm{BNP}(n=6)$. 
A
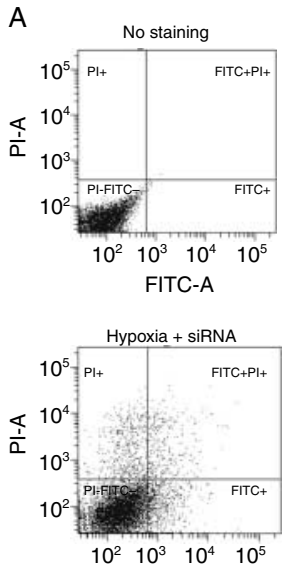

FITC-A
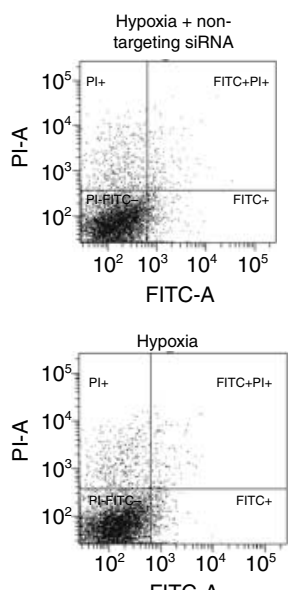

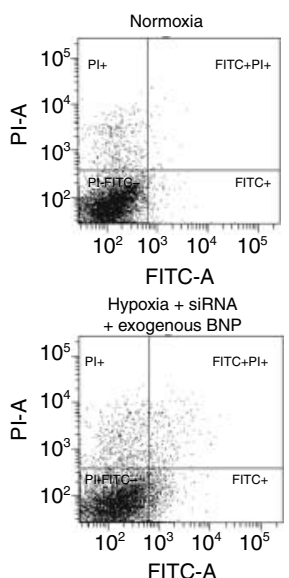

FITC-A
B

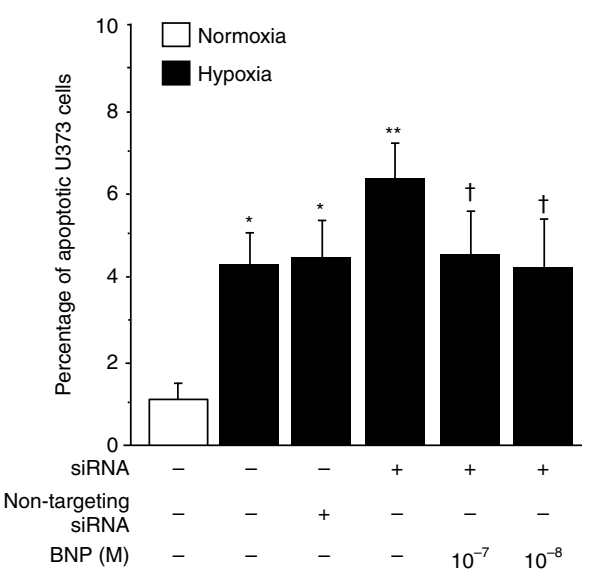

Figure 4 Flow cytometric analysis of apoptosis with annexin-V-FITC and propidium iodide (PI) label in human astrocytoma cell line U373MG. (A) Representative charts of flow cytometry with annexin- $\mathrm{V}$ and PI. (B) Bar graphs show the percentage of apoptotic U373MG cells in total cells under hypoxia with or without BNP knockdown and exogenous $B N P(n=5-6) .{ }^{*} P<0 \cdot 05$ versus normoxia. ${ }^{* *} P<0 \cdot 05$ versus hypoxia. ${ }^{+} P<0 \cdot 05$ versus hypoxia in siRNA without exogenous BNP.

\section{Discussion}

This study demonstrated that BNP was upregulated and released from the human astrocytoma cell line U373MG under hypoxia through $\mathrm{c}-\mathrm{Src}$ activation, and inhibition of $\mathrm{BNP}$ exacerbated hypoxia-induced apoptosis. The administration of exogenous BNP reduced hypoxia-induced apoptosis.

\section{Effect of hypoxia on BNP expression and release in human astrocytoma cell line}

The plasma level of BNP is elevated in patients with stroke, cor pulmonale, pulmonary embolism, and renal failure (Buckley et al. 1992, Bando et al. 1999, Krüger et al. 2004), but the origin of BNP has not been determined. Recently, we have shown that the plasma level of BNP is transiently increased in acute ischemic stroke patients with large artery atherosclerosis independently of heart disease (Tomita et al. 2008), suggesting that BNP may be derived from the ischemic brain. During evolution, neurons have lost many essential metabolic pathways and gained the specialized ability to generate action potentials and communicate by synaptic transmission. Therefore, they depend on the metabolic support from surrounding astrocytes that possess multiple functions such as the release of many transmitters (Takano et al. 2009). We thus focused on astrocytes as the possible origin of BNP, and show that hypoxia increased BNP gene and protein expressions in human astrocytoma U373MG cells. Hypoxia increased BNP protein release from primary cultured astrocytes. The amount of released BNP was increased sevenfold under hypoxia. Since BNP is a secretory peptide, its secretion level appears to be compatible with the several fold increase in gene expression rather than the twofold increase in protein content (cell content).
It was described that reactive oxygen species (ROS) are released from the mitochondria during hypoxia in cardiac myocytes and endothelial cells (Duranteau et al. 1998, Pearlstein et al. 2002), and ROS-induced activation of c-Src is involved in the gene expression of plasminogen activator inhibitor-1 in vascular smooth muscle cells (Sato et al. 2005). Inhibition of protein tyrosine kinase c-Src with genistein blocked hypoxia-induced increase in vascular endothelial growth factor (Mukhopadhyay et al. 1995). Recent reports further showed that c-Src was involved in the activation of the human BNP promoter induced by interleukin- $1 \beta$, isoproterenol, dibutyryl cAMP, and endothelin (He et al. 2000, He \& LaPointe 2001). According to these backgrounds, we investigated the role of c-Src in hypoxia-induced increase in BNP expression in the human astrocytoma cell line U373MG. Being consistent with the findings of other kinds of cells, hypoxia-induced increase in BNP expression and release was abolished by PP1, a specific inhibitor of c-Src. In addition, hypoxia rapidly induced tyrosine phosphorylation of c-Src in the human astrocytoma cell line U373MG. Overall, c-Src appears to be a key molecule in hypoxic induction of BNP in the human astrocytoma cell line U373MG. Tyrosine kinase c-Src activates a number of intracellular signaling pathways such as mitogen-activated protein kinase or Akt signaling. Therefore, these cytokine networks may play an important role in BNP release and other functions of neurons. Further examination is therefore needed.

\section{Role of endogenous BNP}

It is well known that the administration of atrial natriuretic peptide (ANP) exerts beneficial effects in patients with congestive heart failure (Colucci et al. 2000) and in animal 
models of ischemic injury (D'Souza et al. 2003). In PC12 cells, ANP-induced protective signaling of cGMP accounts for the suppression of apoptosis by serum deprivation (Fiscus et al. 2001). Takuma et al. (2001) further showed that cGMP exerted an anti-apoptotic effect to $\mathrm{H}_{2} \mathrm{O}_{2}$ exposure in rat cultured astrocytes, suggesting that BNP may function as an anti-apoptotic molecule via activation of cGMP-dependent signaling pathway. To clarify the role of BNP released from the U373MG cells, we transfected specific siRNA for NPPB and first confirmed that siRNA of annealed BNP blocked $B N P$ gene expression. The result showed that knockdown of BNP increased the number of apoptotic cells in 24 h hypoxia, suggesting that hypoxia-induced increase in BNP attenuated apoptosis of the human astrocytoma U373MG cells in a paracrine or an autocrine fashion. The present finding also unmasked the potential expression of BNP receptor in U373MG cells, thereby raising a possibility of treatment with BNP. To our knowledge, this is the first study to show that BNP may function as an anti-apoptotic molecule in the brain-constituting cells under hypoxia. This is also a unique effect of BNP, since other signaling pathways such as activation of extracellular-regulated kinase and c-Jun $\mathrm{NH}_{2}$ terminal kinase are not involved in apoptosis of U373MG cells (Widmer et al. 2008).

Astrocytes provide metabolic and trophic support to neurons, and their damage could compromise post-ischemic neuronal survival (Bambrick et al. 2004). Therefore, this antiapoptotic effect of BNP appears to play an important role in the brain protection at the acute phase of ischemic stroke. In addition to our work with the blocking siRNA, we further performed complementary studies by treating the cells with exogenous BNP and found that the administration of BNP reversed the activity of caspase in the BNP knockdown cells. Neuroprotective efforts targeting the functional integrity of astrocytes may constitute a superior strategy for neuroprotection. A drawback of using BNP as a potential treatment for ischemic stroke is that the high concentrations necessary to inhibit cell death may affect the growth of latent brain tumors, because $\mathrm{U} 373 \mathrm{MG}$ is derived from the human astrocytoma cells.

\section{Study limitations}

This study showed that in cultured human astrocytoma U373MG cells, BNP expression is upregulated under hypoxia and may function to attenuate apoptosis of the cells in a paracrine or an autocrine fashion. However, since the role of BNP in the pathogenesis of stroke is still poorly understood, further in vivo examinations such as loss-of-function or gainof-function animal studies are needed. Glioma cells are genetically heterogeneous, so there is a possibility that other human glioma cell lines or some cells directly obtained from biopsies might behave differently. Although not fully examined, it was confirmed that the release of BNP was elevated under hypoxia in the primary cultured astrocytes as shown in U373MG cells.
In conclusion, hypoxia increased BNP expression and release in the human astrocytoma cell line U373MG via c-Src activation. Hypoxia-induced increase in BNP may play an important role in brain protection, and this molecular signaling may offer some targets for neuroprotective treatment.

\section{Declaration of interest}

The authors declare that there is no conflict of interest that could be perceived as prejudicing the impartiality of the research reported.

\section{Funding}

This research did not receive any specific grant from any funding agency in the public, commercial, or not-for-profit sector.

\section{Author contribution statement}

$\mathrm{C} \mathrm{K}, \mathrm{T} \mathrm{O}$, and $\mathrm{H} \mathrm{T}$ contributed to the design and performance of the experiment, the analysis of data, and preparation of the manuscript. $\mathrm{K} \mathrm{O}$ contributed to the preparation of the manuscript.

\section{Acknowledgements}

We gratefully thank Prof. Kei Satoh at the Department of Vascular Biology, Institute of Brain Science, Hirosaki University School of Medicine, for excellent advice and support.

\section{References}

Bambrick L, Kristian T \& Fiskum G 2004 Astrocyte mitochondrial mechanisms of ischemic brain injury and neuroprotection. Neurochemical Research 29 601-608. (doi:10.1023/B:NERE.0000014830.06376.e6)

Bando M, Ishii Y, Sugiyama Y \& Kitamura S 1999 Elevated plasma brain natriuretic peptide levels in chronic respiratory failure with cor pulmonale. Respiratory Medicine 93 507-514. (doi:10.1016/S0954-6111(99)90094-X)

Bonow RO 1996 New insights into the cardiac natriuretic peptides. Circulation 93 1946-1950.

Brosnan MJ, Clark JS, Jeffs B, Negrin CD, Van Vooren P, Arribas SM, Carswell H, Aitman TJ, Szpirer C, Macrae IM et al. 1999 Genes encoding atrial and brain natriuretic peptides as candidates for sensitivity to brain ischemia in stroke-prone hypertensive rats. Hypertension 33 290-297.

Buckley MG, Sethi D, Markandu ND, Sagnella GA, Singer DR \& MacGregor GA 1992 Plasma concentrations and comparisons of brain natriuretic peptide and atrial natriuretic peptide in normal subjects, cardiac transplant recipients and patients with dialysis-independent or dialysis-dependent chronic renal failure. Clinical Science 83 437-444.

Chen Y \& Swanson RA 2003 Astrocytes and brain injury. Journal of Cerebral Blood Flow and Metabolism 23 137-149. (doi:10.1097/01.WCB. $0000044631.80210 .3 \mathrm{C})$

Colucci WS, Elkayam U, Horton DP, Abraham WT, Bourge RC, Johnson AD, Wagoner LE, Givertz MM, Liang CS, Neibaur M et al. 2000 Intravenous nesiritide, a natriuretic peptide, in the treatment of decompensated congestive heart failure. Nesiritide Study Group. New England Journal of Medicine 343 246-253. (doi:10.1056/ NEJM200007273430403)

D'Souza SP, Yellon DM, Martin C, Schulz R, Heusch G, Onody A, Ferdinandy P \& Baxter GF 2003 B-type natriuretic peptide limits infarct 
size in rat isolated hearts via $\mathrm{K}_{\mathrm{ATP}}$ channel opening. American Journal of Physiology. Heart and Circulatory Physiology 284 H1592-H1600. (doi:10. 1152/ajpheart.00902.2002)

Duranteau J, Chandel NS, Kulisz A, Shao Z \& Schumacker PT 1998 Intracellular signaling by reactive oxygen species during hypoxia in cardiomyocytes. Journal of Biological Chemistry 273 11619-11624. (doi:10. 1074/jbc.273.19.11619)

Fiscus RR, Tu AW \& Chew SB 2001 Natriuretic peptides inhibit apoptosis and prolong the survival of serum-deprived PC12 cells. Neuroreport 12 185-189. (doi:10.1097/00001756-200102120-00003)

He Q \& LaPointe MC 2001 Src and Rac mediate endothelin-1 and lysophosphatidic acid stimulation of the human brain natriuretic peptide promoter. Hypertension 37 478-484.

He Q, Wu G \& Lapointe MC 2000 Isoproterenol and cAMP regulation of the human brain natriuretic peptide gene involves Src and Rac. American Journal of Physiology. Endocrinology and Metabolism 278 E1115-E1123.

Iadecola C \& Nedergaard M 2007 Glial regulation of the cerebral microvasculature. Nature Neuroscience 10 1369-1376. (doi:10.1038/nn2003)

Iltumur K, Yavavli A, Apak I, Ariturk Z \& Toprak N 2006 Elevated plasma $\mathrm{N}$-terminal pro-brain natriuretic peptide levels in acute ischemic stroke. American Heart Journal 151 1115-1122. (doi:10.1016/j.ahj.2005.05.022)

Kamiya T, Kwon AH, Kanemaki T, Matsui Y, Uetsuji S, Okumura T \& Kamiyama Y 1998 A simplified model of hypoxic injury in primary cultured rat hepatocytes. In Vitro Cellular \& Developmental Biology. Animal 34 131-137. (doi:10.1007/s11626-998-0095-9)

Krüger S, Graf J, Merx MW, Koch KC, Kunz D, Hanrath P \& Janssens U 2004 Brain natriuretic peptide predicts right heart failure in patients with acute pulmonary embolism. American Heart Journal 147 60-65. (doi:10.1016/ S0002-8703(03)00528-3)

Mukhopadhyay D, Tsiokas L, Zhou XM, Foster D, Brugge JS \& Sukhatme VP 1995 Hypoxic induction of human vascular endothelial growth factor expression through c-Src activation. Nature 375 577-581. (doi:10.1038/ 375577a0)

Mukoyama M, Nakao K, Hosoda K, Suga S, Saito Y, Ogawa Y, Shirakami G, Jougasaki M, Obata K \& Yasue H 1991 Brain natriuretic peptide as a novel cardiac hormone in humans. Evidence for an exquisite dual natriuretic peptide system, atrial natriuretic peptide and brain natriuretic peptide. Journal of Clinical Investigation 87 1402-1412. (doi:10.1172/JCI115146)

Nakagawa K, Yamaguchi T, Seida M, Yamada S, Imae S, Tanaka Y, Yamamoto K \& Ohno K 2005 Plasma concentrations of brain natriuretic peptide in patients with acute ischemic stroke. Cerebrovascular Diseases 19 157-164. (doi:10.1159/000083249)

Nedergaard M 1988 Mechanisms of brain damage in focal cerebral ischemia. Acta Neurologica Scandinavica 77 81-101. (doi:10.1111/j.1600-0404.1988. tb05878.x)

Omland T, Aakvaag A, Bonarjee VV, Caidahl K, Lie RT, Nilsen DW, Sundsfjord JA \& Dickstein K 1996 Plasma brain natriuretic peptide as an indicator of left ventricular systolic function and long-term survival after acute myocardial infarction. Comparison with plasma atrial natriuretic peptide and N-terminal proatrial natriuretic peptide. Circulation $\mathbf{9 3}$ 1963-1969.

Pearlstein DP, Ali MH, Mungai PT, Hynes KL, Gewertz BL \& Schumacker PT 2002 Role of mitochondrial oxidant generation in endothelial cell responses to hypoxia. Arteriosclerosis, Thrombosis, and Vascular Biology 22 566-573. (doi:10.1161/01.ATV.0000012262.76205.6A)

Sato H, Sato M, Kanai H, Uchiyama T, Iso T, Ohyama Y, Sakamoto H, Tamura J, Nagai R \& Kurabayashi M 2005 Mitochondrial reactive oxygen species and c-Src play a critical role in hypoxic response in vascular smooth muscle cells. Cardiovascular Research 67 714-722. (doi:10.1016/j.cardiores. 2005.04.017)

Takano T, Tian GF, Peng W, Lou N, Libionka W, Han X \& Nedergaard M 2006 Astrocyte-mediated control of cerebral blood flow. Nature Neuroscience 9 260-267. (doi:10.1038/nn1623)

Takano T, Oberheim N, Cotrina ML \& Nedergaard M 2009 Astrocytes and ischemic injury. Stroke 40 S8-S12. (doi:10.1161/STROKEAHA.108. 533166)

Takuma K, Phuagphong P, Lee E, Mori K, Baba A \& Matsuda T 2001 Anti-apoptotic effect of cGMP in cultured astrocytes: inhibition by cGMP-dependent protein kinase of mitochondrial permeable transition pore. Journal of Biological Chemistry 276 48093-48099. (doi:10.1074/jbc. M108622200)

Tomita H, Metoki N, Saitoh G, Ashitate T, Echizen T, Katoh C, Fukuda M, Yasujima M, Osanai T \& Okumura K 2008 Elevated plasma brain natriuretic peptide levels independently of heart disease in acute ischemic stroke: correlation with stroke severity. Hypertension Research 31 1695-1702. (doi:10.1291/hypres.31.1695)

Widmer M, Hanemann CO \& Zajicek J 2008 High concentrations of cannabinoids activate apoptosis in human U373MG glioma cells. Journal of Neuroscience Research 86 3212-3220. (doi:10.1002/jnr.21757)

Yasue H, Yoshimura M, Sumida H, Kikuta K, Kugiyama K, Jougasaki M, Ogawa H, Okumura K, Mukoyama M \& Nakao K 1994 Localization and mechanism of secretion of B-type natriuretic peptide in comparison with those of A-type natriuretic peptide in normal subjects and patients with heart failure. Circulation 90 195-203.

Zonta M, Angulo MC, Gobbo S, Rosengarten B, Hossmann KA, Pozzan T \& Carmignoto G 2003 Neuron-to-astrocyte signaling is central to the dynamic control of brain microcirculation. Nature Neuroscience 6 43-50. (doi:10.1038/nn980)

Received in final form 20 October 2010

Accepted 25 October 2010

Made available online as an Accepted Preprint 25 October 2010 